\title{
Nutrient solution aeration and growing cycles affect quality and yield of fresh-cut baby leaf red lettuce
}

\author{
Encarnación Conesa ${ }^{a}$, Juan A. Fernández ${ }^{\mathrm{a}, \mathrm{b}}$, Diana Niñirolaa , Catalina Egea-Gilabert ${ }^{\mathrm{b}, \mathrm{c}^{*}}$ \\ aProducción Vegetal, E.T.S. Ingeniería Agronómica, Universidad Politécnica de Cartagena, C/Paseo Alfonso XIII 48, 30203 \\ Cartagena, Spain \\ 'Instituto de Biotecnología Vegetal. Campus Muralla del Mar, Universidad Politécnica de Cartagena, 30202 Cartagena, Spain \\ 'Ciencia y Tecnología Agraria, E.T.S. Ingeniería Agronómica, Universidad Politécnica de Cartagena, C/Paseo Alfonso XIII 48, \\ 30203 Cartagena, Spain \\ e-mail: catalina.egea@upct.es
}

\begin{abstract}
The objective of this research was to study the effects of nutrient solution aeration (no aeration [NA], low aeration [LA] or high aeration [HA]) and growing cycle (autumn, winter and summer) on the yield, quality, and shelf life of red lettuce as a fresh-cut product grown in a floating system. The specific leaf area, yield and root diameter were affected by the growing cycle. The percentage of dry matter and the nitrate content were affected by growing cycle and aeration, total phenolics and mesophilic microorganism by aeration and storage time, hue angle and chromacity by growing cycle and storage time, and antioxidant capacity, vitamin C, lightness and psychrophilic microorganisms were affected by all three factors. NA conditions increased the antioxidant capacity in summer and vitamin C content in winter. The lowest mesophilic and psychrophilic count was observed in autumn. The effect of aeration on most of the quality parameters measured was influenced by the growing cycle.
\end{abstract}

Key words: Lactuca sativa, floating system, colour, postharvest, antioxidant capacity

\section{Introduction}

Lettuce is an important dietary leaf vegetable that is primarily consumed fresh or in salad mixes. Among different production modalities, the "baby leaf" form, presented as whole leaves, 8-12 cm in length, with only one very small section, the petiole, exposed to oxidation, has grown in popularity as minimally processed vegetable products (Rodríguez-Hidalgo et al. 2010). Besides, in comparison with whole-head lettuce, the baby leaf form shows greater efficiency, with a higher percentage of usable product and easier and faster processing; packed, it has a more attractive presentation and suffers minimal oxidation (Martínez-Sánchez et al. 2012). Among the varieties of lettuce, red lettuce has several attractive traits for the consumer, particularly colour and the high contents of phytochemicals with healthy effects (García-Macías et al. 2007). Besides, the red lettuce cultivars generally contain more phenolic compounds and have stronger antioxidant activities than the other lettuce cultivars in the same growing conditions (Liu et al. 2007).

The floating system is an easy and profitable growing technique for the cultivation of baby-leaf vegetable crops. Furthermore, the initial microbial load in leaves in this system at harvesting is lower than in conventionally grown crops (Rodríguez-Hidalgo et al. 2010). Although the floating system is easy to use, it is limited by the concentration of oxygen in the nutrient solution (Carrasco et al. 2011), and plants may suffer hypoxia because the roots gradually consume the oxygen dissolved therein. Furthermore, this effect is more pronounced in the summer when temperatures rise (Morard and Silvestre 1996). A lack of oxygen reduces water and mineral uptake by the plant, which may limit growth and, consequently, crop yield (Tesi et al. 2003). However, there are significant differences in sensitivity to oxygen deficiency in the rooting medium among plant species, and even among cultivars (Veen 1988). Furthermore, the quality of the final product can be affected by metabolic adaptations to oxygen deficiency. It is known that a reduced concentration of oxygen in the nutrient solution of a floating system reduces the nitrate content of rocket (Ferrante et al. 2003), purslane (Lara et al. 2011), lettuce (Tesi et al. 2003) and watercress (Niñirola et al. 2014). A decrease in the nitrate content is important because the maintenance of nitrate concentrations within the foliage at levels below EU maxima is an indicator of the nutritional quality (Konstantopoulou et al. 2010). On the other hand, non-aeration in the nutrient solution increases the antioxidant capacity and total phenolics in purslane, especially in summer, when high temperatures strongly reduce the amount of dissolved oxygen (Lara et al. 2011). Product colour, another very important parameter that influences consumer choice, is affected by the lack of aeration (Tesi et al. 2003, Lara et al. 2011). 
The final quality of the product is also affected by the different environmental factors that occur in different growing seasons. Conte et al. (2008) demonstrated that the lower nitrate content in spinach harvested in March can be explained by the higher temperature regime and sunlight availability during the growing period compared with plants harvested in February. Likewise, Fernández et al. (2012) demonstrated the nitrate content of lettuce leaves was lower in spring cycles than in autumn because of the greater radiation during the cycle as a consequence of the greater nitrate reductase activity associated with greater light intensity (Gaudreau et al. 1995). Also, the production of functional phytochemicals in plants is influenced by environmental factors that may induce stress in plants, since they respond to these stresses by inducing antioxidants as a defence mechanism (Oh et al. 2009). Finally, the colour is also affected by environmental conditions. Conte et al. (2008) suggested that the colour of spinach leaves was influenced by the environmental conditions of the growing period, while Lara et al. (2011) found that purslane leaves had a more intense green colour in summer than in autumn and winter.

In recent years, the fresh-cut industry has tried to prolong shelf-life through postharvest treatments; however maximum postharvest quality can be achieved only by understanding and managing the various roles that preharvest factors play in postharvest quality (Mattheis and Fellman 1999). However, far too little attention has been paid to the effect that cultivation techniques can have on the final stored product. In the present study we evaluate the influence of different levels of nutrient solution aeration during three growing cycles in a floating system on the quality, microbiological load and characteristics of fresh-cut red lettuce "Diveria" at harvesting and after storage.

\section{Material and methods \\ Plant material and growing conditions}

The experiment was conducted at the "Tomás Ferro" Experimental Agro-Food Station, Universidad Politécnica de Cartagena (UPCT) $\left(37^{\circ} 41^{\prime} \mathrm{N}\right.$; $\left.0^{\prime} 57^{\circ} \mathrm{W}\right)$. A cultivar of red baby leaf lettuce (Lactuca sativa L.), var. 'Diveria' from Rijz Zwaan Seeds Company was cultivated in a floating system in an unheated greenhouse covered with thermal polyethylene. Three growing cycles were carried out, with manual sowings on 15 October 2010 (autumn), 4 February 2011 (winter) and 24 June 2011 (summer) in 'stryrofloat' trays containing peat. These trays have pyramidal-trunk $172-\mathrm{mm}$ long fissures $20 \mathrm{~mm}$ apart and grouped in three for a total of 42 fissures per tray. After seedling emergence, the trays were transferred to flotation beds and maintained floating on fresh tap water with an electrical conductivity (EC) of $1.1 \mathrm{dS} \mathrm{m}^{-1}$ and $\mathrm{pH}$ 7.8. Aeration at three levels was provided by a blow pump connected to a pipe trellis positioned at the bottom of each flotation bed. The pipes were perforated with holes at 0,6 or 36 holes $\mathrm{m}^{-2}$ to provide the different levels of aeration to be tested: no aeration (NA), low aeration (LA) and high aeration $(\mathrm{HA})$, respectively. Each level of treatment was carried out in $135 \times 125 \times 20 \mathrm{~cm}$ beds located at three places inside a greenhouse for all the experiments. Each bed had four floating trays of $60 \times 41 \mathrm{~cm}$.

A week after sowing, the lettuce plants were thinned, leaving 10 plants per hole $\left(1,700\right.$ plants $\left.\mathrm{m}^{-2}\right)$. At the same time, the tap water in the beds was replaced with a nutrient solution (Egea-Gilabert et al. 2009). The plants were harvested by hand 27, 26 and 18 days after sowing in autumn, winter and summer, respectively, when the plants had 3-4 leaves. The samples of each treatment were divided in two sets, one for harvest analysis and the other one for postharvest analysis.

The meteorological conditions during the experiment were $7.9^{\circ} \mathrm{C}, 37.6^{\circ} \mathrm{C}, 18.8^{\circ} \mathrm{C}$ minimum, maximum and average air temperature, respectively, for autumn; $8.5^{\circ} \mathrm{C}, 37.5^{\circ} \mathrm{C}$ and $19.7^{\circ} \mathrm{C}$ for winter, and $19.5^{\circ} \mathrm{C}, 41.8^{\circ} \mathrm{C}$ and 27.9 ${ }^{\circ} \mathrm{C}$ for summer. The average daily light integral (DLI) was $11.20 \mathrm{~mol} \mathrm{~m}^{-2} \mathrm{~s}^{-1}$ for autumn, $13.53 \mathrm{~mol} \mathrm{~m}^{-2} \mathrm{~s}^{-1}$ for winter and $18.21 \mathrm{~mol} \mathrm{~m}^{-2} \mathrm{~s}^{-1}$ for summer. The oxygen concentration was monitored using Campbell CS512 sensors located in each flotation bed. The EC and temperature of the nutrient solution were monitored during the growing cycles using Campbell CS547 sensors (Campbell Scientific Inc., Logan, UT, USA).

\section{Analysis at harvesting time}

The specific leaf area (SLA), determined by the relationship between total leaf area and total leaf dry weight, percentage of dry matter, yield and root growth were measured in 20 plants from two fissures randomly chosen from each tray at harvesting time. The total leaf area was measured with a leaf area meter (LICOR 3100 C, Biosciences Inc., Lincoln, USA). The leaf dry matter content was determined by drying in an oven at $60^{\circ} \mathrm{C}$ until constant weight. The colour parameters in leaves were determined using a tristimulus colorimeter $\left(L^{*} a^{*} b^{*}\right.$ colour space) (Minolta CR-10; Konica- Minolta Sensing Inc., Osaka, Japan), calculating the Hue angle $=\arctan \left(b^{*} / a^{*}\right)$ and chromaticity $\left(C^{*}\right)=\left[\left(a^{*}\right)^{2}+\left(b^{*}\right)^{2}\right]^{1 / 2}$. Root lengths and diameters were determined using a Winrhizo LA 1600 root counter (Regent Inc., Quebec, Canada). 
Also, the biochemical parameters detailed below were analyzed. The nitrate content was extracted in triplicate: $0.2 \mathrm{~g}$ of shoot dry samples per treatment were extracted using $50 \mathrm{ml}$ distilled water in an orbital shaker (Stuart SSL1, Stone, UK) for $45 \mathrm{~min}$ at $110 \mathrm{rpm}$ at $50{ }^{\circ} \mathrm{C}$ and quantified by ion chromatography using a Metrosep A SUPP 5 column (Metrohm AG, Zofingen, Switzerland) at a flow rate of $0.7 \mathrm{ml} \mathrm{min}^{-1}$, following the manufacturer's instructions (Lara et al. 2011). For phytochemical extraction three $20 \mathrm{~g}$ shoot fresh weight (FW) samples per treatment and per cycle were frozen in liquid $\mathrm{N}_{2}$ and stored at $-80^{\circ} \mathrm{C}$. Briefly, $0.5 \mathrm{~g}$ of each sample was homogenised in $3.0 \mathrm{ml} 100 \%\left(\mathrm{v} / \mathrm{v}\right.$ ) methanol and centrifuged at 1,200 $\mathrm{g}$ for $15 \mathrm{~min}$ at $4^{\circ} \mathrm{C}$ (Heraeus Fresco 21; Thermo Scientific, Osterode, Germany). The total phenolic content was determined by the Folin-Ciocalteu colorimetric method (Tarazona-Díaz et al. 2011). A $0.1 \mathrm{ml}$ aliquot of the extract supernatant was mixed with $0.15 \mathrm{ml}$ of FolinCiocalteu reagent and $1.0 \mathrm{ml} 4 \mathrm{~g} \mathrm{l}^{-1} \mathrm{NaOH} / 20 \mathrm{~g} \mathrm{I}^{-1} \mathrm{Na}_{2} \mathrm{CO}_{3}$. The absorption of the solution was measured at 750 $\mathrm{nm}$ in a spectrophotometer (SmartSpecTM Plus; Bio-Rad Laboratories, Inc., Hercules, CA, USA). Each measurement was compared with a standard curve of chlorogenic acid and expressed as mg chlorogenic acid equivalent (CAE) $\mathrm{kg}^{-1} \mathrm{FW}$. The antioxidant capacity was evaluated in terms of their free radical-scavenging capacity (BrandWilliams et al. 1995). A fresh solution of $0.7 \mathrm{mM}$ 1,1-diphenyl-2-picryl-hydrazyl (DPPH) radical in $100 \%$ (v/v) methanol was prepared each day. A $0.1 \mathrm{ml}$ aliquot of the extract supernatant was added to $0.9 \mathrm{ml}$ of DPPH stock solution. The absorption of each sample was measured at $515 \mathrm{~nm}$ in a spectrophotometer against a blank of $100 \%(\mathrm{v} / \mathrm{v})$ methanol. Measurements were compared with a standard curve of ascorbic acid concentrations and expressed as $\mathrm{mg}$ ascorbic acid equivalent anti-oxidant capacity (AAE) $\mathrm{kg}^{-1} \mathrm{FW}$. The total vitamin $\mathrm{C}$, extracted from three samples of $0.5 \mathrm{~g}$ of fresh chopped leaves per treatment with $2 \mathrm{ml}$ of $5 \%$ metaphosphoric acid, was determinate by HPLC. The chromatographic system consisted of a Waters 2695 (Waters Corp.) separation module, a column Teknokroma C-18 (Teknokroma S.L.) and detection was carried out at $260 \mathrm{~nm}$ by a UV-Vis detector 2687 (Waters Corp.) (Conesa et al. 2009).

Microbial growth, for both mesophilic and psychrophilic aerobic microorganisms, was assessed following Niñirola et al. (2014). Briefly, samples (10 g fresh weight) from each treatment were blended with $90 \mathrm{ml}$ of sterile tryptone phosphate water (Scharlab, Barcelona, Spain) at pH 7.0 for $1 \mathrm{~min}$ in a sterile bag by using a stomacher. Serial dilutions were prepared in $9 \mathrm{ml}$ tryptone phosphate water. From each dilution, 1-ml aliquots were aseptically pipetted for microbial population counting. Plate count agar (Scharlab) ( $\mathrm{pH} 7.0$ ) for both mesophilic aerobic microorganisms, incubated at $26^{\circ} \mathrm{C}$ for 3 days, and psychrophilic microorganisms, incubated at $4{ }^{\circ} \mathrm{C}$ for 10 days, were used. Duplicates were made for each dilution. Microbial counts were reported as $\log _{10}$ colony-forming units (CFU) per gram of FW.

\section{Post-harvest product management and analysis}

Harvested plants were placed in plastic bags and immediately transported $6 \mathrm{~km}$ in a portable ice box to the Instituto de Biotecnología Vegetal of the UPCT where they were stored for $4 \mathrm{~h}$ at $5{ }^{\circ} \mathrm{C}$. Then, in a disinfected cold room at $10^{\circ} \mathrm{C}$, all leaves free from defects were disinfected by washing for 2 min with a solution containing 100 $\mathrm{ppm} \mathrm{NaOCl}$ and $0.2 \mathrm{~g} \mathrm{l}^{-1}$ citric acid $\left(\mathrm{pH} \mathrm{6.5)}\right.$ at $5{ }^{\circ} \mathrm{C}$. The leaves were rinsed for 2 min under tap water in order to remove residues of $\mathrm{NaOCl}$. Excess surface water was removed in a handheld salad spinner for $30 \mathrm{~s}$. Then, $20 \mathrm{~g}$ of leaves were placed in polypropylene (PP) baskets of 1 I capacity and thermosealed with a $34 \mu \mathrm{m}$ thick film of polyethylene terephthalate (PET) + oriented polypropylene (OPP) and stored at $5{ }^{\circ} \mathrm{C}$ for 7 days.

Changes in $\mathrm{O}_{2}$ and $\mathrm{CO}_{2}$ partial pressures within the baskets were monitored daily throughout storage, by withdrawing a $0.5 \mathrm{ml}$ sample of the headspace from the baskets with a gas-tight syringe and determining $\mathrm{O}_{2}$ and $\mathrm{CO}_{2}$ levels by gas chromatography (Tomas-Callejas et al. 2011).

After 7 days of storage at $5{ }^{\circ} \mathrm{C}$, the colour ( $\mathrm{L}^{*}$, Hue angle and $\left.\mathrm{C}^{*}\right)$, nitrate and total phenol contents, antioxidant capacity and microbial growth were determined as described above.

\section{Experimental design and statistical analysis}

A randomized complete block design with three replicates per level of aeration was used in the greenhouse in all the growing seasons. Data were analysed using Statgraphics Plus. Analysis of variance (three-way ANOVA) was performed in which levels of aeration (NA, LA and HA), growing season (autumn, winter and summer) and storage time ( 0 and 7 days) were included. When the variables were measured at harvesting time, only two factors (aeration and growing season) were included. When interactions were significant, they were included in the ANOVA, and a least significant difference test was performed to compare level of aeration, growing season and storage time. 


\section{Results \\ Monitoring of dissolved oxygen and temperature of the nutrient solution}

The aeration level did not affect the temperature of the nutrient solution in any of the three growing seasons (Fig.1). The growing cycle and the different levels of aeration were two decisive factors for the amount of dissolved oxygen (DO) in the nutrient solution. During the autumn cycle, the mean values of DO were 8.1, 6.2 and $5.2 \mathrm{mg} \mathrm{l}^{-1}$ for HA, LA and NA, respectively. In winter cycle, due to rare high temperatures in the middle of the cycle, the mean values of DO were slightly lower than in the autumn cycle with values of 7.7, 6.7 and $3.9 \mathrm{mg} \mathrm{l}^{-1} \mathrm{for}$ HA, LA and NA, respectively. In the summer cycle, the increased temperature caused a decrease in DO in all the aeration treatments in the nutrient solution. The mean values of DO were 6.9, 5.4 and $3.3 \mathrm{mg}^{-1}$ for $\mathrm{HA}$, LA and NA, respectively (Fig. 1).

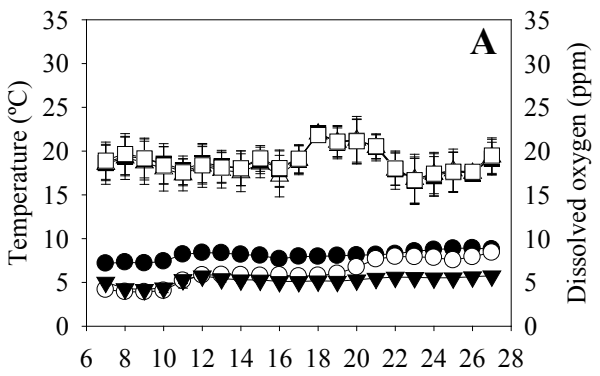

Das
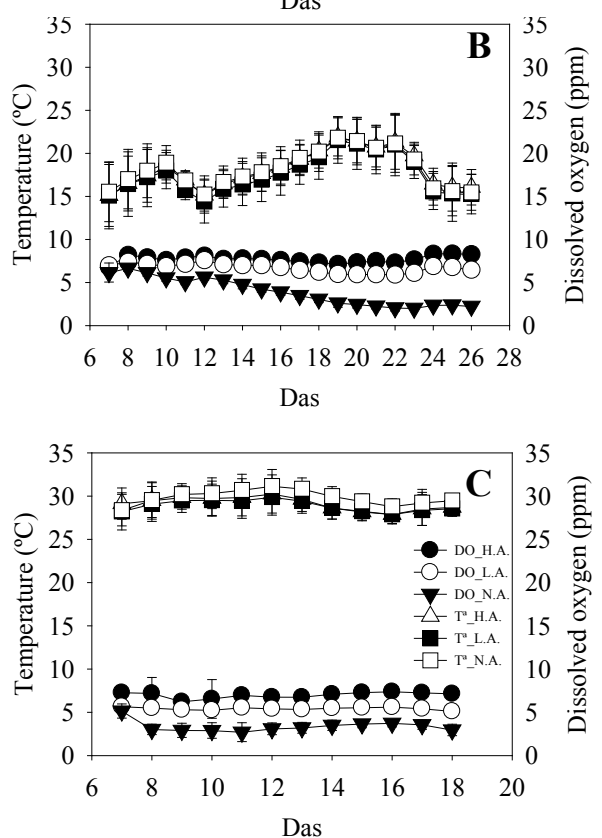

Fig. 1. Evolution of dissolved oxygen (DO) and temperature (Ta) of the nutrient solution under different levels of aeration (no aeration -NA-, low aeration-LA-, high aeration -HA-) in three different growing cycles (autumn -A-, winter -B-, summer -C-). Each datum point for each day after sowing (Das) is the average of 24 hourly measurements $(n=3)$

\section{Growth parameters and yield at harvesting time}

All the growth parameters measured were significantly affected by growing season and some of them by aeration too (Table 1). Statistical analysis pointed to a significant interaction between both factors in the percentage of dry matter, whereas no significant interaction was observed for the rest of the measured parameters (Table 1). 
E. Conesa et al. (2015) 24: 313-322

Table 1. Influence of aeration of the nutrient solution (no aeration -NA-, low aeration -LA-, high aeration -HA-) at harvest on the vegetative plant growth parameters (specific leaf area (SLA), \% dry matter, yield, total root length, root diameter and length of 0 to $1.5 \mathrm{~mm}$ diameter roots) of baby leaf red lettuce cultivated in floating system in autumn, winter and summer cycles

\begin{tabular}{lccccccc}
\hline & \multicolumn{3}{c}{ Season $(\mathrm{A})$} & \multicolumn{3}{c}{ Aeration $(\mathrm{B})$} & \multicolumn{2}{c}{ Interaction } \\
\hline & Autumn & Winter & Summer & NA & LA & HA & AxB \\
Dry matter (\%) & $4.32^{\mathrm{b}}$ & $3.53^{\mathrm{a}}$ & $3.75^{\mathrm{a}}$ & $3.58^{\mathrm{a}}$ & $3.95^{\mathrm{ab}}$ & $4.08^{\mathrm{b}}$ & $*$ \\
$\mathrm{SLA}\left(\mathrm{m}^{2} \mathrm{~kg}^{-1}\right)$ & $81.73^{\mathrm{b}}$ & $42.86^{\mathrm{a}}$ & $79.96^{\mathrm{b}}$ & 68.56 & 71.71 & 64.29 & $\mathrm{~ns}$ \\
Yield $\left(\mathrm{kg} \mathrm{m}^{-2}\right)$ & $2.29^{\mathrm{c}}$ & $1.96^{\mathrm{b}}$ & $1.09^{\mathrm{a}}$ & 1.67 & 1.80 & 1.87 & $\mathrm{~ns}$ \\
Total root length $(\mathrm{m})$ & $0.59^{\mathrm{b}}$ & $0.58^{\mathrm{b}}$ & $0.41^{\mathrm{a}}$ & $0.47^{\mathrm{a}}$ & $0.51^{\mathrm{ab}}$ & $0.60^{\mathrm{b}}$ & $\mathrm{ns}$ \\
Root diameter $(\mathrm{mm})$ & $0.61^{\mathrm{b}}$ & $0.92^{\mathrm{c}}$ & $0.14^{\mathrm{a}}$ & 0.62 & 0.55 & 0.50 & $\mathrm{~ns}$ \\
Length of 0-1.5 mm & $0.56^{\mathrm{b}}$ & $0.53^{\mathrm{b}}$ & $0.39^{\mathrm{a}}$ & $0.44^{\mathrm{a}}$ & $0.47^{\mathrm{ab}}$ & $0.56^{\mathrm{b}}$ & $\mathrm{ns}$ \\
diameter roots $(\mathrm{m})$ & & & & & &
\end{tabular}

Values in each row which do not have any letter in common are significantly different as described by LSD test $(p<0.05)$. Asterisk indicates significances at $*<0.05 ;{ }^{* *} p<0.01 ; * * p<0.001$; ns: non-significant; $\mathrm{n}=20$

Analysis of the interaction between the growing cycle and aeration revealed that neither the cycle nor the aeration level significantly affected the percentage of dry matter (Fig. 2A).
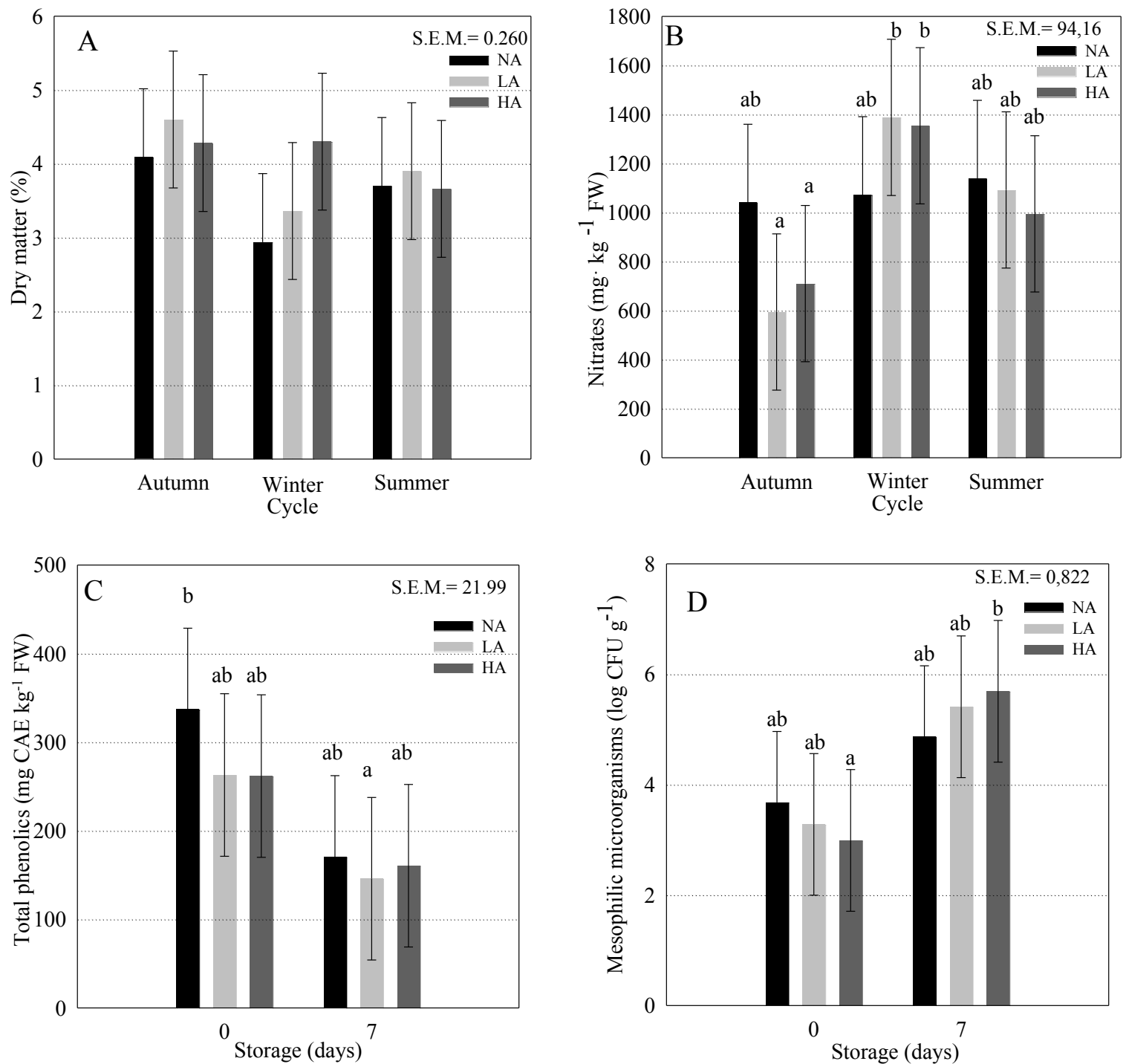

Fig. 2. Effect on \% of dry matter (A) and nitrate content (B) of the aeration level of the nutrient solution (no aeration -NA-, low aeration -LA-, high aeration -HA-) in red lettuce cultivated in floating system, in autumn, winter or summer, and the effect on total phenolics (C) and mesophilic microorganism (D) at harvest or after $7 \mathrm{~d}$ storage at $5{ }^{\circ} \mathrm{C}$. Vertical lines are the least significant difference (LSD) intervals at $p \leq$ 0.05 . Different letters indicate significant differences $(p<0.05)$. A $(n=20), B, C$ and $D(n=3)$

The SLA was significantly lower in the winter cycle compared to autumn and summer. The yield was only significantly affected by the growing cycle, the highest value being obtained in autumn. Total root system was thinner and shorter in summer cycle because of the lower length of 0 to $1.5 \mathrm{~mm}$ diameter roots. The lack of aeration produced shorter total root length but did not affect root diameter (Table 1). 


\section{Quality characteristics of fresh cut lettuce}

The ANOVA showed a significant interaction between the growing cycle and aeration for the nitrate content, between aeration and storage time for total phenolics and mesophilic microorganisms, between growing cycle and storage time for Hue angle and $\mathrm{C}^{*}$, and among all three factors for antioxidant capacity, vitamin $\mathrm{C}, \mathrm{L}^{*}$ and psychrophilic microorganisms (Table 2).

Table 2. Influence of growing cycle (autumn, winter and summer) and aeration of the nutrient solution (no aeration -NA-, low aeration -LA-, high aeration -HA-) on nitrate content, total phenolics, antioxidant capacity, vitamin C, leaf color parameters (lightness $-L^{*}-$, Hue angle and chromaticity $-C^{*}$ ) and microbial growth (mesophilic and psychrophilic microorganisms) of baby leaf red lettuce cultivated in floating system, at harvesting time and after 7 days of storage at $5{ }^{\circ} \mathrm{C}$

\begin{tabular}{|c|c|c|c|c|c|c|c|c|c|}
\hline & $\begin{array}{l}\text { Nitrates } \\
\text { (mg kg }{ }^{-1} \\
\text { FW) }\end{array}$ & $\begin{array}{c}\text { Total } \\
\text { phenolics } \\
\text { (mg CAE kg-1 } \\
\text { FW) }\end{array}$ & $\begin{array}{c}\text { Antioxidant } \\
\text { capacity } \\
\text { (mg AAE } \\
\mathrm{kg}^{-1} \mathrm{FW} \text { ) }\end{array}$ & $\begin{array}{l}\text { Vitamin } \\
\mathrm{C}(\mathrm{mg} \\
\left.\mathrm{kg}^{-1} \mathrm{FW}\right)\end{array}$ & $L^{*}$ & $\begin{array}{l}\text { Hue } \\
\text { angle }\end{array}$ & $C^{*}$ & $\begin{array}{c}\text { Mesophilic } \\
\text { microorganisms } \\
(\log \text { CFU g-1) }\end{array}$ & $\begin{array}{c}\text { Psychrophilic } \\
\text { microorganisms } \\
\left(\log C F U g^{-1}\right)\end{array}$ \\
\hline \multicolumn{10}{|c|}{ Season (A) } \\
\hline Autumn & $781.90^{\mathrm{a}}$ & $243.65^{b}$ & $158.38^{a}$ & $33.67^{a}$ & $29.90^{\mathrm{a}}$ & $54.48^{\mathrm{a}}$ & $16.93^{b}$ & $3.16^{a}$ & $3.01^{\mathrm{a}}$ \\
\hline Winter & $1271.32^{\mathrm{c}}$ & $228.80^{b}$ & $166.85^{a}$ & $151.16^{b}$ & $31.82^{b}$ & $65.92^{\mathrm{a}}$ & $13.046^{a}$ & $4.01^{b}$ & $5.84^{c}$ \\
\hline Summer & $1075.15^{b}$ & $196.70^{\mathrm{a}}$ & $367.51^{b}$ & $26.42^{\mathrm{a}}$ & $35.07^{c}$ & $122.73^{b}$ & $17.24^{\mathrm{b}}$ & $4.18^{b}$ & $4.02^{b}$ \\
\hline \multicolumn{10}{|c|}{ Aeration (B) } \\
\hline NA & 1102.77 & $253.64^{b}$ & $219.64^{a}$ & 76.11 & $31.30^{a}$ & 73.95 & $14.56^{a}$ & 3.81 & $3.91^{\mathrm{a}}$ \\
\hline LA & 1006.24 & $204.40^{\mathrm{a}}$ & $224.61^{\mathrm{a}}$ & 64.39 & $32.87^{b}$ & 83.36 & $15.99^{\mathrm{b}}$ & 3.61 & $4.03^{a}$ \\
\hline $\mathrm{HA}$ & 1019.36 & $211.10^{a}$ & $248.49^{b}$ & 70.74 & $32.60^{\mathrm{b}}$ & 85.81 & $16.66^{b}$ & 3.93 & $4.92^{b}$ \\
\hline \multicolumn{10}{|c|}{ Storage (C) } \\
\hline 0 days & $1587.83^{b}$ & $287.17^{b}$ & $370.70^{b}$ & $93.83^{b}$ & 32.61 & $70.01^{a}$ & $15.17^{a}$ & $3.15^{\mathrm{a}}$ & $3.21^{\mathrm{a}}$ \\
\hline 7 days & $497.75^{a}$ & $158.92^{\mathrm{a}}$ & $91.13^{\mathrm{a}}$ & $47.00^{\mathrm{a}}$ & 31.90 & $92.08^{b}$ & $16.30^{\mathrm{b}}$ & $4.41^{b}$ & $5.36^{b}$ \\
\hline \multicolumn{10}{|c|}{ Interaction } \\
\hline$A \times B$ & $*$ & ns & $* * *$ & $* *$ & ns & ns & ns & ns & $* *$ \\
\hline$A x C$ & $* * *$ & ns & $* * *$ & $* * *$ & $* *$ & $* * *$ & $*$ & ns & $* * *$ \\
\hline $\mathrm{BxC}$ & ns & $*$ & $*$ & ns & ns & ns & ns & $*$ & $* *$ \\
\hline$A \times B \times C$ & ns & ns & $* * *$ & $*$ & $*$ & ns & ns & ns & $*$ \\
\hline
\end{tabular}

Values in each column which do not have any letter in common are significantly different as described by LSD test ( $p<0.05$ ).

Asterisk indicates significances at ${ }^{*} p<0.05 ;{ }^{* *} p<0.01$; ${ }^{* *} p<0.001$; ns: non-significant, ( $\mathrm{n}=3$ for all the measurements except for $L^{*}$, Hue angle and $C^{*}$ when $n=20$ )

The nitrate content was significantly reduced in the autumn cycle compared to the winter cycle in both LA and HA conditions. The lack of oxygen did not affect the nitrate content in any cycle (Fig. 2B).

The total phenolics content was significantly higher in NA at harvest than in LA at postharvest (Fig. 2C). The antioxidant capacity was significantly higher in summer than in autumn and winter cycles for all the aeration treatments at harvest, the highest value being obtained in NA conditions (Table 3). There were no significant differences in the antioxidant capacity among the treatments at 7 days of storage. At harvest, the vitamin $\mathrm{C}$ content was significantly higher in winter compared to autumn and summer cycles for all the aeration treatments, reaching the highest value in NA conditions (Table 3). After $7 \mathrm{~d}$ of storage, the vitamin C content decreased in all treatments. 
Table 3. Interaction (cycle $\mathrm{x}$ aeration $\mathrm{x}$ storage time) in the parameters of antioxidant capacity, vitamin $\mathrm{C}$, lightness ( $\left.\mathrm{L}^{*}\right)$ and psychrophilic microorganisms of red lettuce cultivated in floating system, with different levels of aeration of the nutrient solution (no aeration -NA-, low aeration -LA-, high aeration -HA-) in three growing cycles (autumn, winter and summer), stored at $5^{\circ} \mathrm{C}$ for up to 7 days

\begin{tabular}{|c|c|c|c|c|c|c|c|c|c|c|}
\hline & & & Autumn & & & Winter & & & Summer & \\
\hline \multirow{4}{*}{$\begin{array}{l}\text { Antioxidant } \\
\text { capacity }\end{array}$} & Storage & NA & LA & $\mathrm{HA}$ & NA & LA & $\mathrm{HA}$ & NA & LA & $\mathrm{HA}$ \\
\hline & 0 & 136.49 & 228.31 & 226.99 & 242.76 & 235.89 & 237.09 & 824.29 & 652.65 & 551.82 \\
\hline & 7 & 146.35 & 79.38 & 132.73 & 80.03 & 91.24 & 114.07 & 61.00 & 60.20 & 55.14 \\
\hline & & \multicolumn{9}{|c|}{$\mathrm{SEM}=20.30 \mathrm{LSD}=51.17 \mathrm{n}=3$} \\
\hline \multirow{3}{*}{ Vitamin C } & 0 & 18.57 & 64.87 & 81.29 & 282.32 & 187.34 & 162.99 & 21.42 & 30.54 & 56.45 \\
\hline & 7 & 3.30 & 12.96 & 21.02 & 119.00 & 70.10 & 85.21 & 12.04 & 20.57 & 17.50 \\
\hline & & \multicolumn{9}{|c|}{$\mathrm{SEM}=9.42 \mathrm{LSD}=22.46 \mathrm{n}=3$} \\
\hline \multirow{3}{*}{$L^{*}$} & 0 & 28.37 & 29.64 & 28.85 & 28.68 & 33.89 & 35.3 & 36.97 & 36.63 & 35.2 \\
\hline & 7 & 29.18 & 31.92 & 31.39 & 31.21 & 31.21 & 30.63 & 33.42 & 33.94 & 34.24 \\
\hline & & \multicolumn{9}{|c|}{ SEM= $1.18 \mathrm{LSD}=2.59 \mathrm{n}=20$} \\
\hline \multirow{3}{*}{$\begin{array}{l}\text { Psychrophilic } \\
\text { microorganisms }\end{array}$} & 0 & 0.69 & 0.88 & 2.49 & 4.96 & 5.17 & 5.11 & 2.72 & 1.90 & 5.01 \\
\hline & 7 & 4.09 & 4.94 & 4.95 & 6.30 & 6.72 & 6.76 & 4.72 & 4.54 & 5.20 \\
\hline & & \multicolumn{9}{|c|}{ SEM $=0.27 \mathrm{LSD}=0.64 \mathrm{n}=3$} \\
\hline
\end{tabular}

At harvest, $L^{*}$ was significantly higher in summer in all aeration conditions than in autumn, which means lighter coloured leaves (Table 3 ). Aeration affected $L^{*}$ only in the winter cycle, when the value of this parameter was significantly lower in NA than HA conditions. After $7 \mathrm{~d}$ of storage, the $\mathrm{L}^{*}$ values did not show significant differences between the cycles or the aeration treatments. At harvest, the values of Hue angle were lower in autumn and winter than in summer, which means redder leaves, while $C^{*}$ was significantly higher in summer than in winter, which was reflected in a more vivider colour (data of interaction not shown).

The mesophilic microorganism load increased significantly with storage only in the HA treatment (Fig. 2D). The psychrophilic microbial load showed maximum values in winter, both at harvest and after $7 \mathrm{~d}$ of storage (Table 3 ). After storage, the psychrophilic microbial load increased in all the cycles over harvest time levels.

A steady-state atmosphere within the PP baskets was reached on the third day of storage in all three growing cycles (Fig. 3). No differences in $\mathrm{O}_{2}$ and $\mathrm{CO}_{2}$ levels were observed between aeration conditions during storage. Therefore, respiration rates were only affected by the growing cycle.
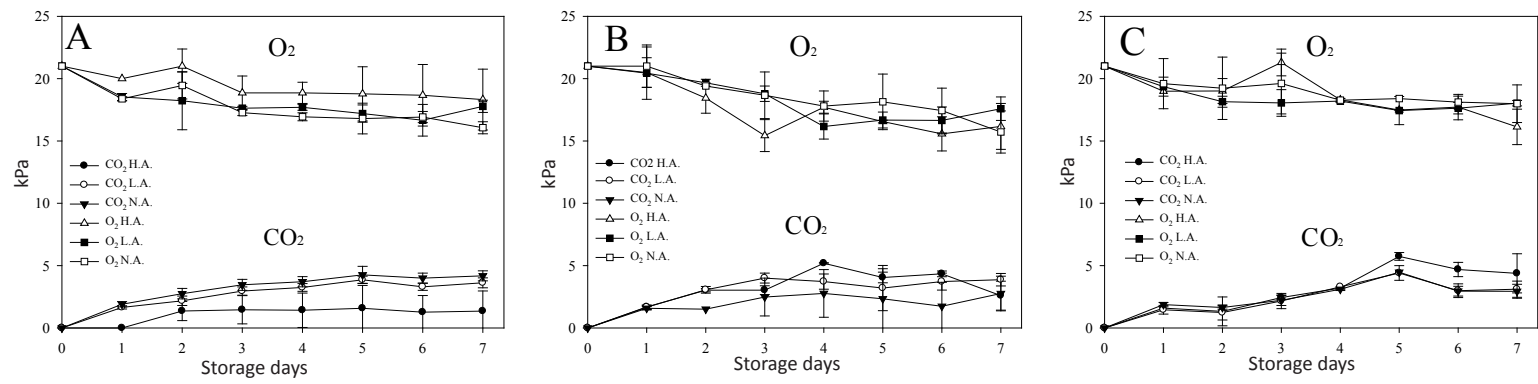

Fig. 3. Influence of the aeration level of the nutrient solution (no aeration -NA-, low aeration-LA-, high aeration -HA-) on the headspace partial pressure of $\mathrm{O}_{2}$ and $\mathrm{CO}_{2}$ within the polypropylene basket of fresh-cut red lettuce cultivated in floating system in three different growing cycles (autumn -A-, winter -B- and summer -C-) and stored for $7 \mathrm{~d}$ at $5{ }^{\circ} \mathrm{C}$. Values are the mean $\pm S D,(n=3)$ 


\section{Discussion}

Agricultural production systems are critical for the yield and quality of fresh-cut products. Our results revealed that red lettuce cultivated in floating system is tolerant to a lack of aeration of the nutrient solution since the yield was not affected (Table 1). This agrees with the results obtained by Goto et al. (1996), who concluded that only DO below $2.1 \mathrm{mg} \mathrm{l}^{-1}$ will reduce the productivity of lettuce. Only in the summer experiment did DO fell below the limit proposed by Goto (1996) due to the high temperatures reached in this cycle. However, in all growing cycles, the DO value was higher than $2.1 \mathrm{mg} \mathrm{l}^{-1}$ at the end of each cycle (Fig. 1). The lowest SLA was obtained in the winter cycle (Table 1). This was not unexpected because SLA values normally decrease with lower radiation (Wolff and Coltman 1990). This fact was true in the case of the autumn cycle with its lower DLI than in winter. In the case of the summer cycle, plants were grown under shading and high temperature conditions, which provoked a lower dry weight per plant and consequently a higher SLA. Total root length increased as aeration of the nutrient solution increased (Table 1). Aeration treatments increase the length of roots, particularly fine roots, improving plant growth (Lara et al. 2011). A similar result was reported by Tesi et al. (2003) in spinach grown in a floating system. Neither the cycle nor aeration affected the percentage of dry matter (Fig. 2A) in agreement with the results obtained by Lara et al. (2011) in purslane growing in a floating system.

The nitrate content was lower in the autumn cycle compared to the winter cycle in LA and HA conditions (Fig. 2B), since light is one of the main factors influencing nitrate concentration, which increases in the plant tissue under poor light conditions (winter) (Burns et al. 2010). The lack of oxygen did not affect the nitrate content in any cycle (Fig. 2B), which contrasts with the results obtained in other species grown in floating systems (Ferrante et al. 2003, Tesi et al. 2003, Lara et al. 2011) where a lack of aeration in the nutrient solution decreased the nitrate concentration.

Among the metabolic adaptations to oxygen deficiency, the results showed that the aeration conditions did not affect the total phenolic content at harvest or postharvest (Fig. 2C). These results agree with those obtained by Niñirola et al. (2014) in watercress and also with those obtained by Lara et al. (2011) in purslane in autumn and spring cycles. The antioxidant capacity was higher in summer, particularly in NA conditions (Table 3), which agrees with the results of Rajapakse et al. (2009), who confirmed that low oxygen stress induced the production of protective phytochemicals in lettuce, which may enhance its marketable value. This response is similar to those observed in purslane and watercress (Lara et al. 2011, Niñirola et al. 2014). Also, the higher antioxidant capacity values reached in summer could be attributed to exposure to high temperature, which is associated with a higher antioxidant capacity (Liu et al. 2007). As regards storage time, the antioxidant capacity at $7 \mathrm{~d}$ was lower than at harvest, which agrees with the results of Rodriguez-Hidalgo et al. (2010) in spinach. The vitamin C content was higher in winter in NA conditions (Table 3 ) as occurred in watercress in NA conditions grown in winter and spring (Niñirola et al. 2014). During storage, a significant decrease in vitamin C was observed due to oxidation, which is exacerbated with increasing storage temperature and time (Konstantopoulou et al. 2010). In addition, the vitamin $C$ content of fruits and vegetables can be influenced by various factors such as genotypic differences, preharvest climatic conditions and cultural practices, maturity and harvesting methods, and postharvest handling procedures (Lee and Kader 2000).

Colour is important quality parameter in lettuce (Simonne et al. 2002) and is based, in part, on anthocyanin and chlorophyll levels. However, the pigments causing that give rise to the red colour of lettuce leaves are mainly anthocyanins, whose contents are genotype-, temperature- and light-dependents (Kleinhenz et al. 2003). More particularly, lettuce leaf pigment concentrations and growing temperatures are negatively related. In our study lettuce grown in autumn and winter, with lower temperatures than in summer, had lower hue angle values (Table 2). Since, increases in hue angle are associated with decreases in anthocyanin levels (Gazula et al. 2007), lettuce produced in autumn and winter had a higher content of anthocyanins, and consequently, were redder. Since the percentage of red color varied in the different growing cycles, the degradation pigment process, i.e. formation of pheophytin from chlorophyll, could have had an effect on the $\mathrm{L}^{*}$ values at $7 \mathrm{~d}$ of storage (Table 3 ).

Among the intrinsic factors that should be examined to ensure the quality of horticultural products are the hygienic conditions. Our results indicate that the microbial load never exceeded $6 \log \mathrm{CFU} \mathrm{g}^{-1}$ at the end of storage (Table 2) a value similar to that obtained in iceberg lettuce or lettuce hearts (Abadias et al. 2008) or in a romaine lettuce (Oliveira et al. 2010). The lowest mesophilic and psychrophilic count was observed in autumn, probably due to the climatic conditions, because low temperatures were reached in this cycle (Conte et al. 2008). The HA conditions increased the microbial population (Table 2), especially psychrophilic microorganisms in winter and summer (Table 3) and after storage in the case of mesophilic microorganisms (Fig. 2D). This fact could have been caused by the splashing of nutrient solution onto lettuce leaves by vigorous aeration. Normally, microorganisms 
E. Conesa et al. (2015) 24: 313-322

increase their populations during storage, as has been observed in spinach (Conte et al. 2008) and different varieties of lettuce (Oliveira et al. 2010, Selma et al. 2012). In our work, this was observed in the case of psycrophilic microorganisms due to the storage temperature used, while the mesophilic microorganisms load did not increase in NA or LA because of the storage temperature was not ideal for their growth.

The steady-state atmospheres reached within packages of leaves after diverse aeration treatments during growing were quite similar and ranged from $15-19 \mathrm{kPa} \mathrm{O}_{2}$ and $1-4 \mathrm{kPa} \mathrm{CO}$ (Fig. 3). This result suggests that film permeability was relatively high and that the aeration supplied to the hydroponic system was not a critical factor to the respiration behaviour after harvest.

In conclusion, aeration did not affect yield, which was highest in autumn because plants grew with non-limiting DO levels at the three aeration levels. This was due to the better climatic conditions for lettuce during the autumn cycle (temperate temperature and low lighting) compared with other cycles. The effect of aeration on the quality parameters was differentially influenced by the other factors analysed. Thus, the effect of aeration on the nitrate content depended on the growing cycle, the effect on total phenolics depended on the storage time and the effect on the antioxidant capacity, and vitamin C content depended on both growing cycle and storage time. In general, the nitrate content fell in the autumn cycle, while not aerating the nutrient solution (NA) led to increased levels of levels of phytochemical compounds.

\section{References}

Abadias, M., Usall, J., Anguera, M., Solsona, C. \& Viñas, I. 2008. Microbiological quality of fresh, minimally-processed fruit and vegetables and sprouts from retail establishments. International Journal of Food Microbiology 123: 121-129.

Brand-Williams, W., Cuvelier, M.E. \& Berset, C. 1995. Use of a free radical method to evaluate antioxidant activity. LWT - Food Science and Technology 28: 25-30.

Burns, I.G., Zhang, K., Turner, M.K., Meacham, M., Al-Redhiman, K., Lynn, J., Broadley, M.R., Hand, P. \& Pink, D. 2010. Screening for genotype and environment effects on nitrate accumulation in 24 species of young lettuce. Journal of the Science of Food and Agriculture 91: 553-562.

Carrasco, G., Gajardo, J.M., Álvaro, J.E. \& Urrestarazu, M. 2011. Rocket production (Eruca sativa Mill.) in a floating system using per acetic acid as oxygen source compared with substrate culture. Journal of Plant Nutrition 34: 1397-1401.

Conesa, E., Niñirola, D., Vicente, M.J., Ochoa, J., Bañón, S. \& Fernández, J.A. 2009. The influence of nitrate/ammonium ratio on yield quality and nitrate, oxalate and vitamin $\mathrm{C}$ content of baby leaf spinach and bladder campion plants grown in a floating system. Acta Horticulturae 843: 269-274.

Conte, A., Conversa, G., Scrocco, C., Brescia, I., Laverse, J., Elia, A. \& Del Nobile, M.A. 2008. Influence of growing periods on the quality of baby spinach leaves at harvest and during storage as minimally processed produce. Postharvest Biology and Technology 50: 190-196.

Egea-Gilabert, C., Fernández, J.A., Migliaro, D., Martínez-Sánchez, J.J. \& Vicente, M.J. 2009. Genetic variability in wild vs. cultivated Eruca vesicaria populations as assessed by morphological, agronomical and molecular analyses. Scientia Horticulturae 121: 260-266.

Fernández, J.A., Esteban, A., Conesa, E., Ochoa, J. \& Álvarez-Rogel, J. 2012. Nitrate evolution in soil, leaching water, and lettuce plant crops using different fertilization strategies. Communications in Soil Science and Plant Analysis 43: 2467-2483.

Ferrante, A., Incrocci, L., Maggini, R. \& Tognoni, F. 2003. Preharvest and postharvest strategies for reducing nitrate content in rocket (Eruca sativa). Acta Horticulturae 628: 153-159.

Garcia-Macias, P., Ordidge, M., Vysini, E., Waroonphan, S., Battey, N.H., Gordon, M.H., Hadley, P., John, P., Lovegrove, J.A. \& Wagstaffe, A. 2007. Changes in the flavonoid and phenolic acid contents and antioxidant activity of red leaf lettuce (Lollo Rosso) due to cultivation under plastic films varying in ultraviolet transparency. Journal of Agricultural and Food Chemistry 55: 68-72.

Gaudreau, L., Charbonneau, J., Vezina, L.P. \& Gosselin, A. 1995. Effects of photoperiod and photosynthet1c photon flux on nitrate content and nitrate reductase activity in greenhouse-grown lettuce. Journal of Plant Nutrition 18: 437-453.

Gazula, A., Kleinhenz, M.D., Scheerens, J.C. \& Ling, P.P. 2007. Anthocyanin levels in nine lettuces (Lactuca sativa) cultivars: influence of planting date and relations among analytic, instrumented, and visual assessments of color. Hortscience 42: 232-238.

Goto, E. 1996. Effect of dissolved oxygen concentration on lettuce growth in floating hydroponics. Acta Horticulturae 440: $205-21$.

Kleinhenz, M.D., French, D.G., Gazula, A. \& Scheerens, J.C. 2003. Variety, shading and growth stage effects on pigment concentrations in lettuce grown under contrasting temperature regimens. HortTechnology 13: 677-683.

Konstantopoulou, E., Kapotis, G., Salachas, G., Petropoulos, S.A., Karapanos, I.C. \& Passam, H.C. 2010. Nutritional quality of greenhouse lettuce at harvest and after storage in relation to $\mathrm{N}$ application and cultivation season. Scientia Horticulturae 125: 93-95.

Lara, L., Egea-Gilabert, C., Niñirola, D., Conesa, E. \& Fernández, J.A. 2011. Effect of aeration of the nutrient solution on the growth and quality of purslane (Portulaca oleracea). Journal of Horticultural Science \& Biotechnology 86: 603-610.

Lee, S.K. \& Kader, A.A. 2000. Preharvest and postharvest factors influencing vitamin C content of horticultural crops. Postharvest Biology and Technology 20: 207-220.

Liu, X., Ardo, S., Bunning, M., Parry, J., Zhou, K., Stushnoff, C., Stoniker, F., Yu, L. \& Kendall, P. 2007. Total phenolic content and DPPH radical scavenging activity of lettuce (Lactuca sativa L.) grown in Colorado. LWT - Food Science and Technology 40: 552-557. 
Martínez-Sánchez, A., Luna, M.C., Selma, M.V., Tudela, J.A., Abad, J. \& Gil, M.I. 2012. Baby-leaf and multi-leaf of green and red lettuces are suitable raw materials for the fresh-cut industry. Postharvest Biology and Technology 63: 1-10.

Mattheis, J.P. \& Fellman, J.K. 1999. Preharvest factors influencing flavour of fresh fruit and vegetables. Postharvest Biology and Technology 15: 227-232.

Morard, P. \& Silvestre, J. 1996. Plant injury to oxygen deficiency in the root environment of soilless culture: A review. Plant and Soil 184: 243-254.

Niñirola, D., Fernández, J.A., Conesa, E., Martínez, J.A. \& Egea-Gilabert, C. 2014. Combined effects of growth cycle and different levels of aeration in nutrient solution on productivity, quality, and shelf life of watercress (Nasturtium officinale R. Br.) plants. Hortscience 49: 567-573.

Oh, M., Carey, E.E. \& Rajashekar, C.B. 2009. Environmental stresses induce health-promoting phytochemicals in lettuce. Plant Physiology and Biochemistry 47: 578-583.

Oliveira, M., Usall, J., Solsona, C., Alegre, I., Viñas, I. \& Abadias, M. 2010. Effects of packaging type and storage temperature on the growth of foodborne pathogens on shredded 'Romaine' lettuce. Food Microbiology 27: 375-380.

Rajapakse, N.H., Cisneros-Zevallos, C.L. \& Davies, F.T. 2009. Hypobaria and hypoxia affects growth and phytochemical contents of lettuce. Scientia Horticulturae 122: 171-178.

Rodríguez-Hidalgo, S., Artés-Hernández, F., Gómez, P., Fernández, J.A. \& Artés, F. 2010. Quality of fresh-cut baby spinach grown under a floating trays system as affected by nitrogen fertilization and innovative packaging treatments. Journal of the Science of Food and Agriculture 90: 1089-1097.

Selma, M.V., Luna, M.C., Martínez-Sánchez, A., Tudela, J.A., Beltrán, D., Baixauli, C. \& Gil, M.I. 2012. Sensory quality, bioactive constituents and microbiological quality of green and red fresh-cut lettuces (Lactuca sativa L.) are influenced by soil and soilless agricultural production systems. Postharvest Biology and Technology 63: 16-24.

Simonne, A., Simonne, E., Eitenmiller, R. \& Coker, C.H. 2002. Bitterness and composition of lettuce varieties grown in the southeastern United States. HortTechnology 12: 721-726.

Tarazona-Díaz, M.P., Viegas, J., Moldao-Martins, M. \& Aguayo, E. 2011. Bioactive compounds from flesh and by-product of freshcut watermelon cultivars. Journal of the Science of Food and Agriculture 91: 805-812.

Tesi, R., Lenzi, A. \& Lombardi, P. 2003. Effect of salinity and oxygen level on lettuce grown in a floating system. Acta Horticulturae 609: 383-387.

Tomas-Callejas, A., Lopez-Velasco, G., Camacho, A.B., Artes, F., Artes-Hernandez, F. \& Suslow, T.V. 2011. Survival and distribution of Escherichia coli on diverse fresh-cut baby leafy greens under preharvest through postharvest conditions. International Journal of Food Microbiology 151: 216-222.

Veen, B.W. 1988. Influence of oxygen deficiency on growth and function of plant roots. Plant and Soil 111: 259-266.

Wolff, X.Y. \& Coltman, R.R. 1990. Productivity of eight leafy vegetable crops grown under shade in Hawaii. Journal of the American Society for Horticultural Science 115: 182-18. 